\title{
Measurement of Indoor Radon Concentration in Some Selected Offices of Adigrat University, Tigray Region, Ethiopia
}

\author{
Nigus Alene Assefa ${ }^{*}$, Munaj Kumar Bhardwaj ${ }^{*}$ \\ Department of Physics, Mekelle University, Tigray, Ethiopia \\ Email address: \\ nigusalene@gmail.com (N. A. Assefa), mkbhardwaj1000@gmail.com (M. K. Bhardwaj) \\ ${ }^{*}$ Corresponding author
}

To cite this article:

Nigus Alene Assefa, Munaj Kumar Bhardwaj. Measurement of Indoor Radon Concentration in Some Selected Offices of Adigrat University, Tigray Region, Ethiopia. Radiation Science and Technology. Vol. 5, No. 2, 2019, pp. 11-14. doi: 10.11648/j.rst.20190502.11

Received: September 3, 2019; Accepted: September 29, 2019; Published: October 10, 2019

\begin{abstract}
Radon is an inert radioactive gas. A long term exposure to high concentration of radon causes lung cancer. Taking this into account, an investigation in some offices of Adigrat Universityhas been made to estimate the radon concentrations and to determine the health risk of the workers in the community. In the present study, Solid State Nuclear Track Detectors (LR115 type II) has been used to measure the emission of radon from 12 offices for a period of 3 months. After an exposure time of 3 months, films were removed from each office andtaken for etching. After the etching, films were washed with distilled water and allowed to dry for 1day. Finally, alpha tracks were counted using an optical microscope at magnification power of 400X. Results obtained in the present study show that the value of concentration of radon ranges from $171.31 \mathrm{~Bq} \cdot \mathrm{m}^{-3}$ to 394.05 Bq. $\mathrm{m}^{-3}$ with mean concentration $273.79 \mathrm{~Bq} \cdot \mathrm{m}^{-3}$ and standard deviation of $79.7 \mathrm{~Bq} \cdot \mathrm{m}^{-3}$ and the inhalation dose rate varies from a minimum of $1.54 \mathrm{mSv} \cdot \mathrm{y}^{-1}$ to a maximum of $3.55 \mathrm{mSv} \cdot \mathrm{y}^{-1}$ with an average of $2.46 \mathrm{mSv} \cdot \mathrm{y}^{-1}$ and standard deviation of 0.72 $\mathrm{mSv} \cdot \mathrm{y}^{-1}$. Even though, radon concentration levels were found to be higher the inhalation dose rate is safe within recommended limits
\end{abstract}

Keywords: Radon Concentration, LR-115 Plastic Track Detectors, Offices

\section{Introduction}

The knowledge of the radioactivity level in building materials is important in order to estimate the radiological hazards on human health. It has been found that radon, which is a topic of health concern, is a ubiquitous indoor air pollutant in dwellings to which all persons are exposed. Radon is naturally occurring radioactive noble gas which has no test, odor or color. It produced by the decay of Radium which is foundin rocks, soils and building materials. It comes from the natural decay of uranium 238 series, with atomic number 86 and mass number 222 . It was discovered by the German physicist Friedrich Ernst Dorn in 1900, who called it niton. It has been called radon since 1923. Radon condenses to a clear colorless liquid at its boiling point and then freezes to form a yellow, then orange red color solid. Radon is also moderately soluble in water and, therefore, can be absorbed by water flowing through rock and sand containing radon. Its solubility depends on the water temperature, the colder the temperature of water the greater the radon's solubility. Its decay products called radon daughters or radon progeny emit highlyionizing alpha-radiation. Decay products are suspended in the air which we breathe. Although the risk is very low when radon is diluted to extremely low concentrations in the open, radon in room air typically contributes up to $50 \%$ to the background radiation. However, in places such as caves and mines, it can accumulate up to dangerous concentrations and may cause substantial health damage after long-term exposure. Radon can also be found in drinking water and this can sometimes present a hazard.

Certain types of geology, such as granite and volcanic soils, as well as aluminous shale's, are more likely to contain radon. Conversely, low concentrations of this gas are expected in sedimentary rocks.

Radon being a gas can migrate by mechanism of diffusion and convection throughpore spaces in the soil, and enter the 
atmosphere, thus, reaching the human environment [1-4]. Lung cancer is the principal health concern associated with radon exposure. About half of the total radiation effective dose to the general public isdue to the irradiation of the lungs by alpha particles. Continuous exposure to higher levels of radon leads to malignant transformation which results in lung cancer [5]. The level of exposure to radon in the building depends on ventilation in the building and local geology [67]. The studies of radon's behavior in the geological environment have indicated that there is a direct relationship between indoor radon levels and concentration of the gas in soil. Windows and doors which are not air-tight lead to a greater air exchange rateand if the basement or other soilcontacting parts of the building areopenitmakes easy for radon to spread upwards [8]. In present study investigations have beencarried out to measure the radon concentrations in some offices in AdigratUniversity, Ethiopia using Solid State Nuclear Track Detectors (LR-115 type II).

\section{Area Under Investigation}

Adigrat University is a higher education and training public institution located in the city of Adigrat, situated in the Eastern Tigray Regional State of Ethiopia at longitude and latitude $14^{\circ} 16^{\prime} \mathrm{N} 39^{\circ} 27^{\prime}$ ECoordinates with an elevation of 2,457 meters $(8,061 \mathrm{ft})$ above sea level and below a high ridge to the west. It is approximately 900 kilometers north of Addis Ababa, the country's capital [9-10].

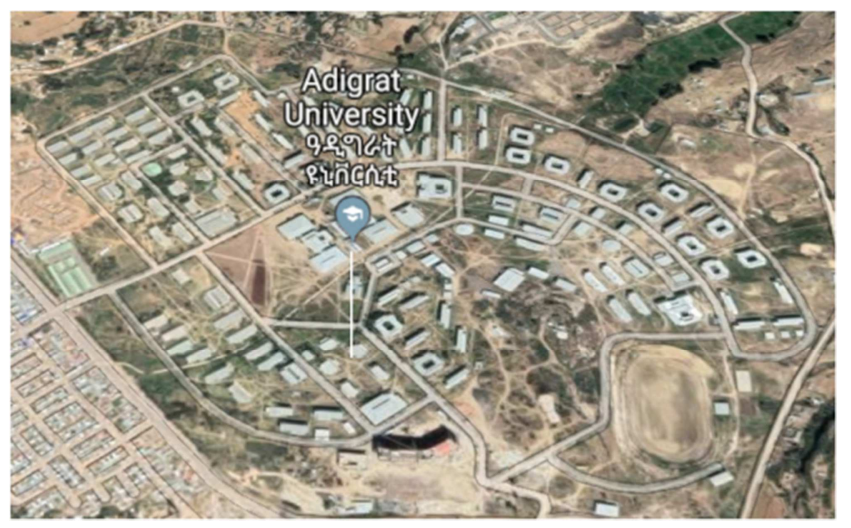

Figure 1. Map of Adigrat University.

\section{Experimental Procedure}

In the present study, the measurements of radon concentration in offices were carried out by using the LR115 Type II, plastic track detectors. These plastic film detectors of size $2 \mathrm{~cm} \times 3 \mathrm{cmwere}$ hanging at $1 \mathrm{~m}$ away from the roof of offices. Detectors were exposed for a 3 months in ventilated, partially ventilated and unventilated offices. After an exposure time of 3 months, films were removed from each officeand taken to Mekelle University for etching. Films were etched with $2.5 \mathrm{~N} \mathrm{NaOH}$ solution at $65^{\circ} \mathrm{C}$ for 90 minutes. The etching was carried out to reduce the thickness of the LR-115 detectors to about $5 \mu \mathrm{m}$. After theetching, films were washed with distilled water and allowed to dry for 1day. Finally, alpha tracks were counted using an optical microscope at magnification of 400x.

\section{Results and Discussion}

Radon concentration $\left(\mathrm{C}_{\mathrm{Rn}}\right)$ is measured in terms of $\mathrm{Bq} / \mathrm{m}^{3}$, since the concentrations were found by using the following expressions[11-12].

$\rho=\frac{N}{A}$, Where $\rho$ is track density, $\mathrm{N}$ is number of tracks and $\mathrm{A}$ is the area of the detector film (LR-115).

The potential alpha energy concentration $\mathrm{Cp}(\mathrm{mWL})$ is given by the formula,

$$
\mathrm{C}_{\mathrm{p}}(\mathrm{mWL})=\frac{\rho}{K T}
$$

$\mathrm{mWL}$ is mili working level which is the unit of $\mathrm{Cp}, \mathrm{K}$ is the average value of the calibration factor of ${ }^{222} R n$ in (tracks. $\mathrm{cm}^{-2}$ )/ (days.Bq. ${ }^{3}$ ) and $\mathrm{T}$ is the exposure time(day).

The concentration of radon and the potential alpha energy concentration is also given by;

$$
\mathrm{C}_{\mathrm{Rn}}\left(\mathrm{Bq} \cdot \mathrm{m}^{-3}\right)=\frac{3.7 C_{p}}{F}
$$

Where $\mathrm{F}=0.4$ is equilibrium factor.

The inhalation dose $\mathrm{D}_{\text {in }}$ (in $\mathrm{mSv} \cdot \mathrm{y}^{-1}$ ) was calculated using the equation;

$$
\mathrm{D}_{\text {in }}\left(\text { in } \mathrm{mSv} \cdot \mathrm{y}^{-1}\right)=0.009 \mathrm{C}_{\mathrm{Rn}}
$$

\begin{tabular}{|c|c|c|c|c|c|}
\hline Detector code & Track density $\rho\left(\right.$ tracks.cm $\left.{ }^{-2}\right)$ & Nature ofventilation & CP(MwL) & $\mathrm{CRn}\left(\mathrm{Bq} \cdot \mathrm{m}^{-3}\right)$ & $\operatorname{Din}(\mathrm{mSv} / \mathrm{y})$ \\
\hline D-1 & 33.33 & Excellent & 18.52 & 171.31 & 1.54 \\
\hline D-2 & 40 & Moderate & 22.22 & 205.54 & 1.85 \\
\hline D- 3 & 66.67 & Poor & 37.04 & 342.62 & 3.08 \\
\hline D-4 & 63.33 & Moderate & 35.18 & 325.42 & 2.93 \\
\hline D-5 & 36.67 & Partial & 20.37 & 188.42 & 1.70 \\
\hline D-6 & 55 & Moderate & 30.55 & 282.59 & 2.54 \\
\hline D-7 & 68.33 & Poor & 37.96 & 351.13 & 3.16 \\
\hline D-9 & 53.33 & Moderate & 29.63 & 274.08 & 2.47 \\
\hline D-10 & 35 & Excellent & 19.44 & 179.82 & 1.62 \\
\hline D-11 & 76.67 & Poor & 42.60 & 394.05 & 3.55 \\
\hline D-12 & 37.67 & Very Good & 20.93 & 193.60 & 1.74 \\
\hline
\end{tabular}

Table 1. Observed values of track density, potential alpha energy concentration, radon concentrations and inhalation rates. 


\begin{tabular}{|c|c|c|c|c|c|}
\hline Detector code & Track density $\rho\left(\right.$ tracks.cm $\left.{ }^{-2}\right)$ & Nature ofventilation & CP(MwL) & $\operatorname{CRn}\left(B q \cdot m^{-3}\right)$ & $\operatorname{Din}(\mathrm{mSv} / \mathrm{y})$ \\
\hline Mean & 53.28 & - & 29.60 & 273.79 & 2.46 \\
\hline Standard deviation & 15.5 & & 8.6 & 79.7 & 0.72 \\
\hline
\end{tabular}

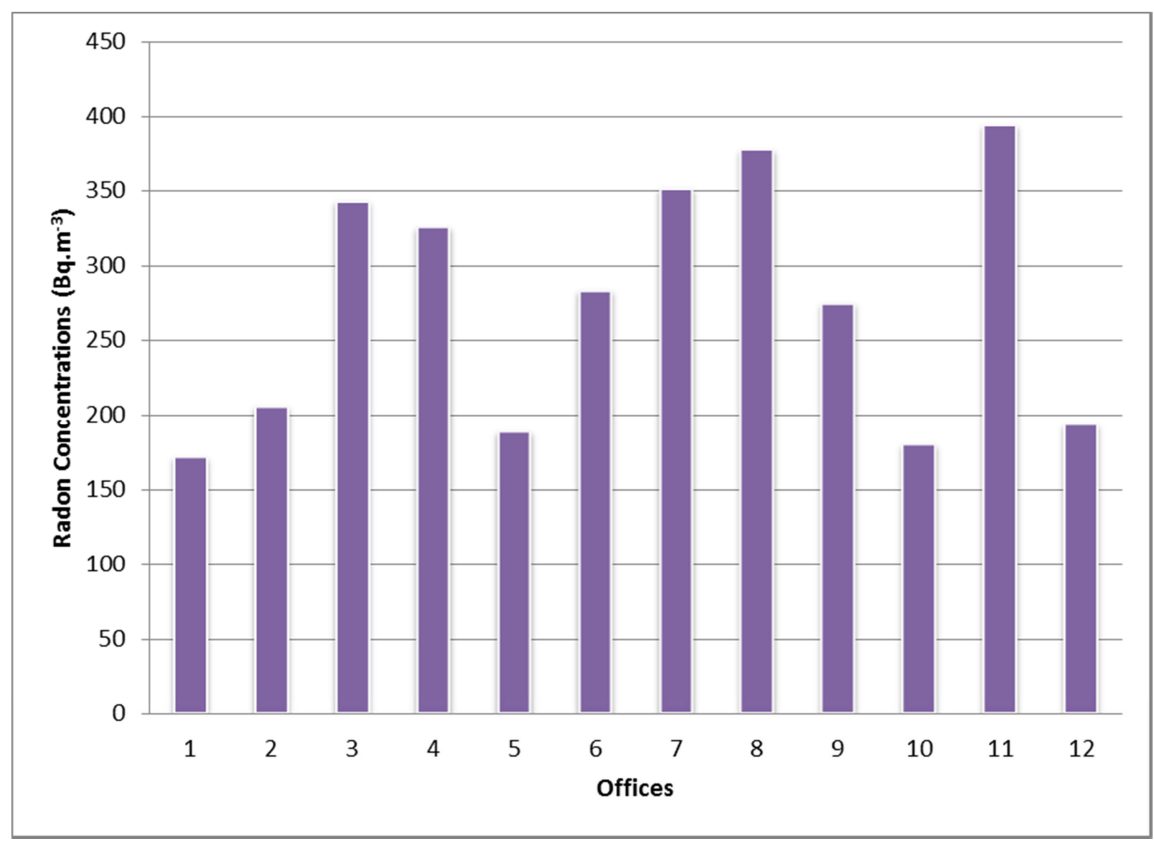

Figure 2. Frequency distribution of radon concentration in offices.

Figure 2 shows the Frequency distribution of radon concentrations in dwellings of Adigrat University. There is a linear correlation appeared throughout the figure, this finding is reported for the first time from the study area.

Table 1 shows the number of LR-115 detectors, observed values of track density, potential alpha energy concentration, radon concentrations and inhalation rates. Radon concentrations were found to range from a minimum value 171.31 Bq.m ${ }^{-3}$ to a maximum value 394.05 Bq. $\mathrm{m}^{-3}$ with mean values of $273.79 \mathrm{~Bq} . \mathrm{m}^{-}{ }^{3}$ and standard deviation of 79.7Bq. $\mathrm{m}^{-3}$. Inhalation dose rate varies from a minimum of $1.54 \mathrm{mSv} . \mathrm{y}^{-1}$ to a maximum of $3.55 \mathrm{mSv} \cdot \mathrm{y}^{-1}$ with an average of $2.46 \mathrm{mSv} \cdot \mathrm{y}^{-1}$ and standard deviation of $0.72 \mathrm{mSv}^{-1}{ }^{-1}$ The obtained values of radon concentration are higher than the recommended limits whereas, inhalation dose rate is within the safe limits. From the result observed the variation of radon concentration is high. The high radon level in some offices suggests that the difference in air dilution, ventilation system, building materials used (like mud and cements) and mood of construction of offices influence the indoor radon levels. Occupants in that area are expected to expose to a high level of doses with a potential risk of lung cancer. After completion of the countrywide radon assessments a detail comparison of results will be available.

\section{Conclusion}

Radon concentrations were found to range from a minimum value $171.31 \mathrm{~Bq} \cdot \mathrm{m}^{-3}$ to a maximum value 394.05 Bq. $\mathrm{m}^{-3}$ with mean values of $273.79 \mathrm{~Bq} \cdot \mathrm{m}^{-}{ }^{3}$ and standard deviation of $79.7 \mathrm{~Bq} \cdot \mathrm{m}^{-3}$. Inhalation dose rate varies from a minimum of $1.54 \mathrm{mSv} \cdot \mathrm{y}^{-1}$ to a maximum of $3.55 \mathrm{mSv}^{-1}$ with an average of $2.46 \mathrm{mSv} \cdot \mathrm{y}^{-1}$ and standard deviation of $0.72 \mathrm{mSv}^{-1} \mathrm{y}^{-}$. The obtained values of radon concentration are higher than the recommended limits whereas, inhalation dose rate is within the safe limits. From the result observed the variation of radon concentration is high. From the results found it may be concluded that the observed values of radon concentrations in the offices of Adigrat university arehigher while, annual effective dose are within the safe limit as prescribed by InternationalCommission on Radiological Protection (ICRP) recommends an action level of 200 Bq. $\mathrm{m}^{-3}$ forradon and annual effective dose of 3-10 mSv/y [13].

\section{Acknowledgements}

The authors would like to thank Mekelle University for providing materialsfor this research and to Adigrat University for allowing us to do. Authors also acknowledge to Dr. Alem Mebrahtu, vice president of Adigrat University for his contribution to the success of this work. Thanks to all staff and management of the Adigrat University, especiallythose who willingly helped in theplacement of the detectors in their offices.

\section{References}

[1] Mohamed Abd-Elzaher, An Overview on Studying ${ }^{222} \mathrm{Rn}$ Exhalation Rates using Passive Technique Solid-State Nuclear Track Detectors. American Journal of Applied Sciences 9 (10): 1653-1659, 2012 ISSN 1546-9239. 
[2] Bajawa, D., A. K. Goswami I. Laskar, 2009. Radon exhalation rate studies in Makum coalfield area using track-etched detectors. Indian J. Phys., 83:1155-1162. DOI: 10.1007/s12648-009-0095-y.

[3] M. Shakir Khan, A. H. Naqvi1, A. Azam, D. S. Srivastava, Radium and radon exhalation studies of soil, Iran. J. Radiat. Res., 2011; 8(4): 207-210.

[4] Irene Opoku-Ntim, Aba BentilAndam, O. C. Oppon, Akwasi Bonsu Asumadu-Sakyi and Frank Kobla Quashie, Survey of Indoor Radon Levels at Several Districts in Ghana, Elixir Nuclear \& Radiation Phys. 80 (2015) 31162-31164.

[5] Navjeet Sharma, Rajesh Sharma and H. S. Virk, Environmental radioactivity: A case study of Punjab, India, Pelagia Research Library, Advances in Applied Science Research, 2011, 2 (3):186-190, ISSN: 0976-8610.

[6] R. C. Ramolaand T. V. Ramachandran, Variation of Radon and Thoron Levels in Garhwal Homes, National Institute of Radiological Sciences, Division of Radiotoxicology and Protection4-9-1 Anagawa, Inage-ku, Chiba-shi, 263-8555, Japan.
[7] D. E. Martz, A. S. Rood, J. L. George and Jr. H. Langer, Year to Year Variation in Annual Average Indoor ${ }^{222} \mathrm{Rn}$ Concentrationa. Health Phys. 61, 409-413 (1991).

[8] Ali AbidAbojassim and Asia H. Al. Mashhadani, Study the Concentrations of Radon indoor at Different Times of the Day and Seasons of the Year in Al-Najaf City/Iraq, Elixir Nuclear \& Radiation Phys. 85 (2015) 34171-34175.

[9] Gebrelibanos, Tsegay (2003). "Addigrat". In Uhlig, Siegbert. Encyclopaedia Aethiopica. 1. Wiesbaden: Harrassowitz Verlag.

[10] http://www.adu.edu.et/about-us/

[11] Samir Mohamed; "Investigation of radon pollution in grow and water in the southern part of gaza strip palestine", Islamic University-Gaza-Palestine, 2007-1428, Palestine, 2007.

[12] Al-Koahi M., Khader B., Lehlooh A., Kullab M., Abumurad K., and Al-Bataina B "Measurement of Radon -222 in Jordanian Dwellings", Nucl., Tracks Radiation Measurement, 20, 1992, pp:377-382.

[13] ICRP. Protection Against Radon-222 at Home and at Work. Publication 65. Annals of theICRP Vol. 23 No. 2; 1993. 